\title{
A STRUCTURAL TIME SERIES MODEL OF NEVADA GROSS TAXABLE GAMING REVENUES
}

\author{
J. S. Shonkwiler*
}

\begin{abstract}
Nevada gross taxable gaming revenues constitute an important revenue source for the state, just as revenues from lottery sales and taxable sales of service industries make major contributions to the general funds of other states. Typically, these data series are nonstationary and can exhibit periods of accelerating growth. The local linear, or stochastic, trend is proposed as an alternative to other time series methods such as the VAR approach. The inherent feature of the stochastic trend is that it provides a local approximation to a linear trend by allowing the level and slope to evolve over time according to a random walk mechanism. This type of structural time series model was used to forecast gaming revenues. It was found that forecasting performance exceeded that of a VAR model and that forecasts were adaptable to changing business conditions.
\end{abstract}

Nevada's gaming industry plays a prominent role in the economic organization of the state. ${ }^{1}$ It has been suggested that 60 percent of Nevada employment is in some way tied to the gaming industry (Cargill and Morus 1988). Direct taxes on gaming activity alone account for more than 40 percent of the state's general revenue. Thus, accurate forecasts of gross taxable gaming revenues could benefit the state's budgetary process by providing direct information on future gaming tax revenues and indirect information on trends in sales and employment tax collections.

Taxes on casino gaming revenues currently provide substantial contributions to state coffers in Nevada and New Jersey only. However, the rapid expansion of legalized gambling in other locations (riverboat casinos along the Mississippi River, video slot machines in Oregon, and localized gambling in Colorado and South Dakota) will likely stimulate more interest in forecasting these revenues. In addition, 32 states permit some type of lottery, with Florida leading the nation by generating $\$ 2.14$ billion in fiscal 1991 lottery sales. But revenues or sales generated by all gambling activities are unique only to the extent that the markets for these services are either highly regulated or governmentally controlled. Thus, many of the same problems associated with forecasting the taxable sales of a state's service sector are probably encountered in the analysis of gambling revenues.

In a recent survey, Connaughton and Madsen (1990) compared several different types of forecasting models, but failed to consider structural time series

\footnotetext{
Professor of Agricultural Economics at the University of Nevada, Reno. The helpful comments of T. F. Cargill, G. A. Horton, and anonymous referees are acknowledged. Research supported by the Nevada Agricultural Experiment Station.
} 
models, which have the ability to represent local linear (stochastic) trends and stochastic seasonality. These models appear to have particular relevance when the data series of interest is nonstationary (LeSage 1990), as would be expected of many regional time series measures. This study presents a structural time series model of quarterly gross taxable gaming revenues. ${ }^{2}$ The model is estimated over and forecasts are developed for two different time periods so that the strengths and weaknesses of the approach used can be better understood. But before the model is developed, it is necessary to address several issues regarding the nature of the data and the time period analyzed. Proceeding in this manner will facilitate assessment of the structural time series model as well as models that have been suggested by other analysts.

\section{THE DATA}

Figure 1 depicts quarterly gross taxable gaming revenues for the period 1967-I through 1990-IV. The major feature of this data series is the pronounced growth. A second feature, which is somewhat obscured by the scale used, pertains to the seasonal pattern within most years. Uniformly, the third quarter exceeds the others with the second, fourth, and first following, though not consistently in that order.

Closer inspection of the data reveals that growth has not been constant. Figure 2 shows the percentage growth for each quarter relative to the corresponding quarter a year prior. Except for the fourth quarter of 1982, year-over-year growth in revenues has been positive, though variable. It is precisely this variability that

FIGURE 1

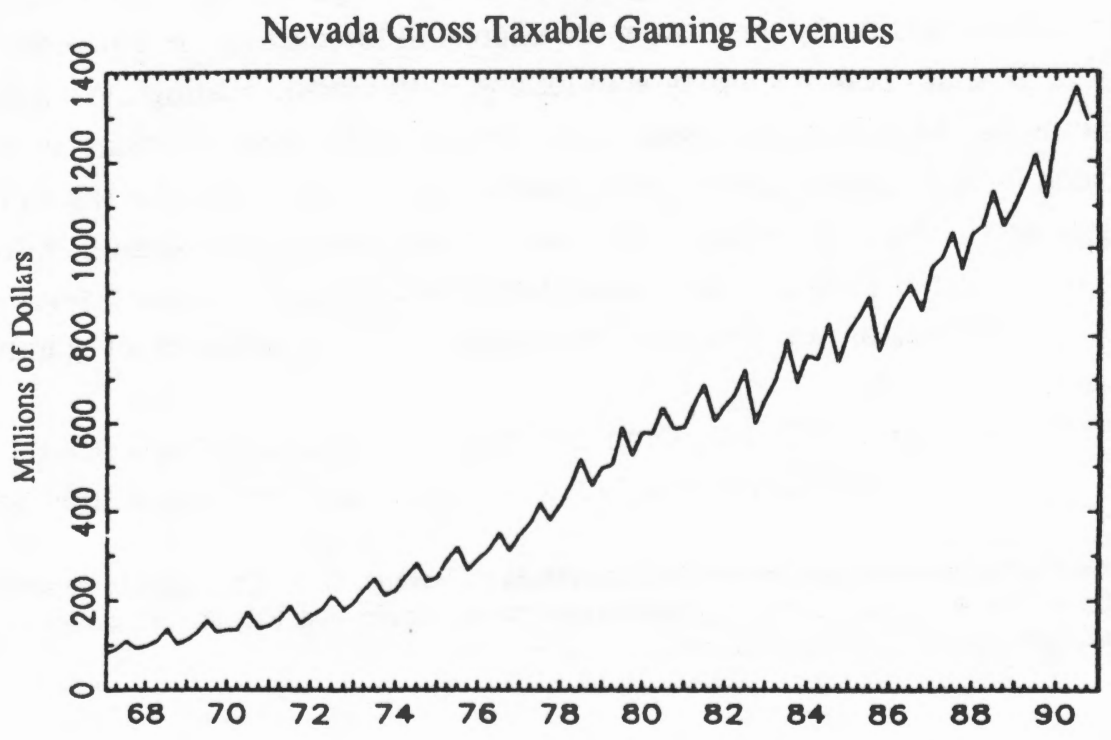


suggests that deterministic models of this series would fail to provide useable forecasts.

Some of this variability is due to changing levels of gaming activity (measured by the drop and the handle), ${ }^{3}$ to changing types of games played (various table games versus slot machines), and consequently to the win percentage and to changing levels of credit play. These observations follow from the definition of gross taxable gaming revenues as gross winnings less unrepaid credit play. Gross winnings depend on the amount wagered and the rate of win. The win rate depends on the types of games played and is controllable by the casino in the case of slot machine play and may be influenced by the casino in the case of table games.

FIGURE 2

Gaming Revenue Growth Rates

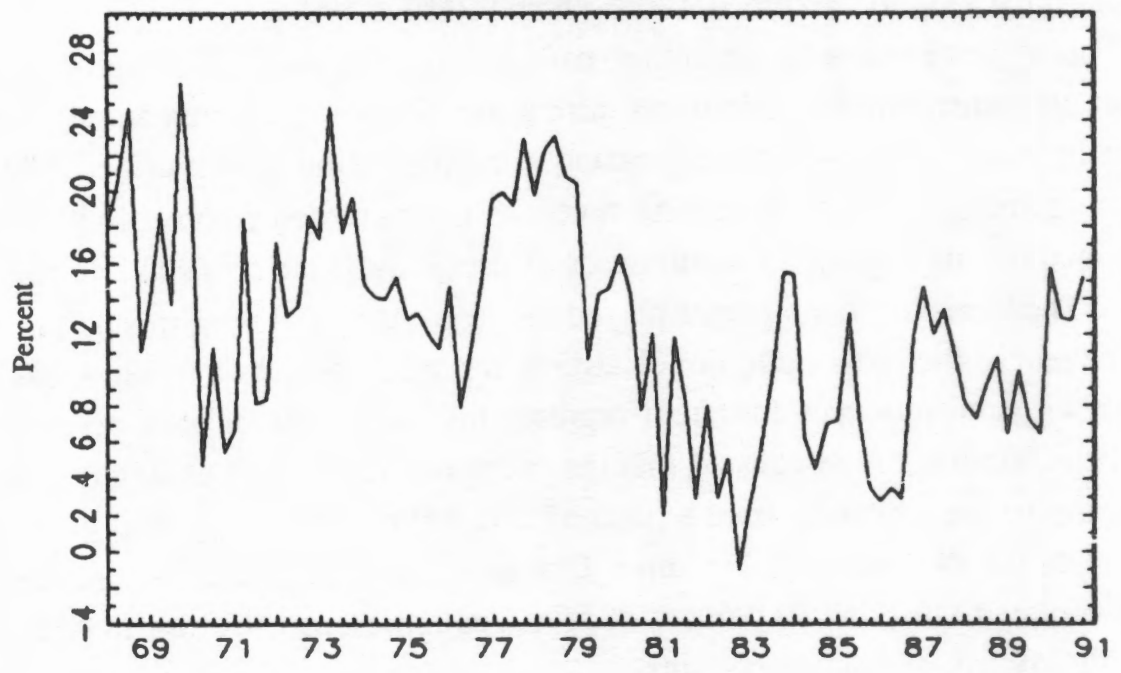

Because of the multiplicity of factors that can affect quarterly gross taxable gaming revenue, Horton (undated) has argued that it is an inappropriate measure to forecast due to its artificial nature. However, a disaggregate approach to computing taxable revenues would require models for wagering, win rate, and credit play, as well as for their (nonlinear) interaction. While such detail would allow the explicit incorporation of different events in the separate models, the complexity may not justify the effort. Moreover, gross taxable gaming revenues may be directly interpreted as total consumer gambling expenditures (losses), since they represent the difference between amounts wagered and amounts won. Therefore, analysis will be undertaken using the gross taxable gaming series with the awareness that it represents a number of complex factors. 


\section{THE CONTEXT}

The 24-year period from 1967 through 1990 saw remarkable events transpire that had profound impacts on Nevada's gaming industry. The period coincides with the beginning of corporately held gaming licenses, although it was 1969 before a workable law was passed (Eadington and Hattori 1978). This provided casinos access to a national capital market and spurred the growth of new and expanded operations. Concurrently, the population in California, whose residents comprise about 45 percent of the Nevada gaming market, expanded by more than 10 million residents, and per capita income there grew faster than the national average. Although studies published in the 1970 s provided mixed evidence of the impact of the business cycle on gaming revenues (Cargill and Eadington 1978; Cargill 1979), more recent analysis has suggested that aggregate economic fluctuations have a significant impact (Cargill and Raffiee 1990).

Public perceptions of gambling have changed as well (Thompson 1985). Numerous states introduced lotteries during this period (California among them), and in 1978, Atlantic City initiated casino gambling. Although the effect of Atlantic City gaming on Nevada gaming revenues has not been rigorously analyzed, some analysts downplay its significance (Cargill and Raffiee 1990; Horton undated). The types of casino games played has also changed during this period, due in large part to the introduction of electronic slot machines. As a result, gross taxable table game revenues fell from representing two-thirds of total revenues to two-fifths. Horton has suggested that the enforcement in 1985 of Regulation 6a, pertaining to the reporting transactions of $\$ 10,000$ or more, may also have contributed to the demise of table games. One aspect of this change is that the win rate associated with the 60 percent of revenues represented by slot machines is under the control of casino operators.

To various degrees, these events have shaped the character and extent of casino gaming in Nevada and have consequently impacted gross taxable gaming revenues. They should also raise questions about how adequately time series models can portray the time path of a variable that comprises so many components in a dynamic environment.

\section{THE MODEL}

The preceding discussion was aimed at motivating the notion that the level and growth of gross taxable gaming revenues are evolving over time in a nondeterministic fashion. The basic structural time series model proposed to capture this evolution is the variable, or stochastic, trend model. This model has been 
widely promulgated by Harvey (1989). Stock and Watson (1988) have also provided a lengthy justification for the importance of this type of model for analyzing economic time series. The basic model is represented by three equations:

$$
\begin{aligned}
& Y_{t}=\mu_{t}+\varepsilon_{t} \\
& \mu_{t}=\mu_{t-1}+\beta_{t-1}+\eta_{t} \\
& \beta_{t}=\beta_{t-1}+\zeta_{t}
\end{aligned}
$$

The first equation relates the $t^{\text {th }}$ observation $(t=1,2, \ldots$ T) of the observed series to an unobserved component, $\mu_{t}$, representing the level of the series and a structural error, $\varepsilon_{t}$. The second equation shows that the level of the series is related to its previous value plus a growth rate, $\beta_{t-1}$, and an error, $\eta_{\mathrm{t}}$. This last term indicates that the level of the series is stochastic. The final equation shows that the growth rate also is evolving and contains a stochastic element, $\zeta_{t}$. To complete the stochastic specification, we assume that the elements of the vector $\left[\varepsilon_{t}, \eta_{t}, \zeta_{t}\right]$ are independently and identically distributed with means of zero and variancecovariance matrix:

$$
\left[\begin{array}{ccc}
\sigma_{\varepsilon}^{2} & 0 & 0 \\
0 & \sigma_{\eta}^{2} & 0 \\
0 & 0 & \sigma_{\zeta}^{2}
\end{array}\right]
$$

As specified, the model depends upon only three parameters, $\sigma_{\varepsilon}^{2}, \sigma_{\eta}^{2}, \sigma_{\zeta}^{2}$. If $\sigma_{\eta}^{2}=\sigma_{\zeta}^{2}=0$, then the observed series evolves according to:

$$
\begin{aligned}
& Y_{1}=\mu_{1}+\varepsilon_{1} \\
& \mu_{1}=\mu_{0}+\beta_{0} \\
& \beta_{1}=\beta_{0}
\end{aligned}
$$

where $\mu_{0}$ and $\beta_{0}$ denote the initial conditions. At time $t$, the model can be expressed as:

$$
Y_{t}=\mu_{t}+\varepsilon_{t}=\mu_{0}+\beta_{0} t+\varepsilon_{t}
$$

or more familiarly as a deterministic trend model. If $\sigma_{\zeta}^{2}=0$, then it can be shown that:

$$
\begin{aligned}
& Y_{t}=\mu_{t}+\beta_{0} t+\varepsilon_{t} \\
& \mu_{t}=\mu_{t-1}+\eta_{t}
\end{aligned}
$$


which suggests that the level of the series is stochastic but the growth rate is not. In this case, it would typically be expected that $\beta_{0}$ is not significantly different from zero.

The reduced form associated with the basic model in Equations (1) through (3) can be obtained by successive differencing of the measurement Equation (1) and substitution of terms. This yields:

$$
\begin{aligned}
\Delta y t= & \Delta \mu_{t}+\Delta \varepsilon_{t}=\beta_{t-1}+\Delta \varepsilon_{t}+\eta_{t} \\
\Delta^{2} y t & =\Delta \beta_{t-1}+\Delta^{2} \varepsilon_{t}+\Delta \eta_{t} \\
& =\Delta^{2} \varepsilon_{t}+\Delta \eta_{t}+\zeta_{t-1} \\
& =\varepsilon_{t}-2 \varepsilon_{t-1}+\varepsilon_{t-2}+\eta_{t}-\eta_{t-1}+\zeta_{t-1}
\end{aligned}
$$

Thus, the reduced form is a restricted $\operatorname{ARIMA}(0,2,2)$. If $\sigma_{\varepsilon}^{2}=\sigma_{\eta}^{2}=0$, then the reduced form is ARIMA $(0,2,0)$, or in other words, $y_{t}$ is a doubly integrated process. Finally, if $\sigma_{\zeta}^{2}=0$, then the structural system is as in Equation (6), and the reduced form is ARIMA $(0,1,1)$.

Although the basic structural model depends on only three parameters (and the initial conditions $\mu_{0}$ and $\beta_{0}$ ), it embodies a number of important specifications. Of particular value is that the model provides a means for testing whether a series is trend stationary $\left(\sigma_{\eta}^{2}=\sigma_{\zeta}^{2}=0\right)$ or difference stationary $\left(\sigma_{\eta}^{2}\right.$ and/or $\left.\sigma_{\zeta}^{2} \neq 0\right)$. Nelson and Kang (1981) point out that regressing a difference stationary series against time will result in the incorrect inference that time is a statistically significant variable. Furthermore, regressions on the levels of difference stationary variables that are not co-integrated (Engle and Granger) can result in a host of asymptotic divergences involving both parameters and test statistics (Durlauf and Phillips 1988; Stock and Watson 1988). The inherent feature of the basic structural model is that it provides a local approximation to a linear trend by allowing the level and slope to change slowly over time according to a random walk mechanism (Harvey 1989).

Seasonality may be introduced in the basic structural model by constructing quarterly dummy (binary) variables and respecifying (1) as:

$$
Y_{t}=\mu_{t}+\delta_{1} d_{1 t}+\delta_{2} d_{2 t}+\delta_{3} d_{3 t}+\varepsilon_{t}
$$

where the $\mathrm{d}_{i t}$ are the dummy variables, and the $\delta_{i}$ are the associated parameters. A characteristic of this specification is the assumption that the seasonal patterns are constant over the sample. However, examination of the data does not bear this out, so the approach of Harvey and Todd is adopted. Following their development, a process is presumed to generate the seasonal components according to: 


$$
\delta_{t}=-\sum_{j=1}^{3} \delta_{t-j}+\omega_{t}
$$

where $\omega_{t}$ is independently and identically distributed with mean zero, and the variance is $\sigma_{\omega}^{2}$. This formulation allows the seasonal components to evolve over time by a mechanism that guarantees that the sum of the seasonal components over any four consecutive quarters has an expected value of zero (Harvey and Todd 1983). If $\sigma_{\omega}^{2}=0$, then the seasonal components are considered nonstochastic, and a specification similar to (9) may be used.

\section{THE RESULTS}

Under the assumption that the elements of the vector of the disturbances [ $\varepsilon_{t}$, $\left.\eta_{t}, \zeta_{t}, \omega_{t}\right]$ were normally distributed independent of white noise processes, the structural model with seasonal components was estimated using maximum likelihood methods (Harvey 1989). Structural parameters estimated over the period 1967-I through 1987-IV are presented in Table 1. The statistical significance of $\sigma_{\eta}^{2}$ can be interpreted as meaning the quarterly gross taxable gaming revenue series is difference stationary (follows a random walk). The statistical significance of $\sigma_{\omega}^{2}$ suggests that the seasonal pattern has not been constant over the period of estimation. Model assessment is aided by the inclusion of a standard squared coefficient of determination as well as $R_{\Delta 4}^{2}$, which measures the reduction in variance the model provides relative to the variance of the series $Y_{t}-Y_{t-4}$. The measure $\rho(1)$ accounts for the level of first order autocorrelation of the estimated innovations (residuals), and the Box-Ljung statistic is a test that the in-

TABLE 1

Parameter Estimates for Period 1967-I through 1987-IV.

\begin{tabular}{lrc}
\hline \hline Parameter & Estimate & Standard Error \\
\hline$\sigma_{\varepsilon}^{2}$ & 33.180 & 32.50 \\
$\sigma_{\eta}^{2}$ & 118.400 & 48.70 \\
$\sigma_{\xi}^{2}$ & 1.105 & 1.18 \\
$\sigma_{\omega}^{2}$ & 12.290 & 5.99 \\
\hline $\mathrm{R}^{2}=.996$ & & \\
$R_{\Delta 4=.623}^{2}$ & & \\
$\rho(1)=-.012$ & & \\
Box-Ljung (12) $=11.28$ & &
\end{tabular}


novation series is white noise. It is distributed as chi-square with 12 degrees of freedom.

The period of estimation was chosen in order to provide out-of-sample forecasts to coincide with those of Cargill and Raffiee. A comparison of forecasts is presented in Table 2. The one-step ahead forecasts of the structural time series model may be compared directly with the forecasts of Cargill and Raffiee's BVAR model, since both sets of forecasts use knowledge of lagged dependent variables over the forecast period. On the other hand, the multistep forecasts of the structural time series model use only information available through 1987-IV. Thus, as expected, forecast accuracy tends to deteriorate as the forecast horizon lengthens, yet the stochastic trend model still provides a better forecast record in terms of average absolute percentage error than the Cargill-Raffiee benchmark over the forecast period analyzed. ${ }^{4}$ Of course, this is not a guarantee that the structural time series model would perform comparably over other periods.

TABLE 2

Out-of-Sample Forecasts 1988-I through 1989-III.

\begin{tabular}{|c|c|c|c|c|c|c|c|}
\hline \multirow{2}{*}{$\frac{\text { Quarter }}{88-I}$} & \multirow{2}{*}{$\begin{array}{l}\text { Actual } \\
1034.9\end{array}$} & \multicolumn{2}{|c|}{$\begin{array}{l}\text { One-Step Ahead } \\
\text { Forecasts }\end{array}$} & \multicolumn{2}{|c|}{$\begin{array}{l}\text { Multistep Ahead } \\
\text { Forecasts }\end{array}$} & \multicolumn{2}{|c|}{$\begin{array}{c}\text { Cargill-Raffiee } \\
\text { Forecasts } \\
\end{array}$} \\
\hline & & 1026.4 & $(.8)^{\mathrm{a}}$ & 1026.5 & $(.8)$ & 1035 & $\overline{(0.0)}$ \\
\hline 88-II & 1050.9 & 1057.0 & $(-.6)$ & 1051.1 & $(-.02)$ & 1076 & (2.4) \\
\hline 88-III & 1133.0 & 1108.7 & $(2.1)$ & 1106.4 & (2.3) & 1149 & (1.4) \\
\hline 88-IV & 1050.9 & 1037.0 & (1.3) & 1019.0 & (3.0) & 1067 & (1.5) \\
\hline 89-I & 1101.1 & 1129.3 & $(-2.6)$ & 1095.8 & $(.5)$ & 1157 & (5.1) \\
\hline 89-II & 1155.6 & 1129.4 & $(2.3)$ & 1120.5 & (3.0) & 1197 & (3.6) \\
\hline 89-III & 1214.5 & 1212.4 & (.2) & 1175.7 & (3.2) & 1263 & (4.0) \\
\hline \multicolumn{2}{|c|}{$\begin{array}{l}\text { Average absolute } \\
\text { percentage error }\end{array}$} & \multicolumn{2}{|c|}{$1.4 \%$} & \multicolumn{2}{|c|}{$1.8 \%$} & \multicolumn{2}{|c|}{$2.6 \%$} \\
\hline
\end{tabular}

${ }^{2}$ Percentage error of the forecast.

In fact, the recession of 1991 may constitute a test of the structural time series model's ability to forecast given a change in general business conditions. To this end, the model was reestimated through 1990-IV. These results are given in Table 3. Note that neither $\sigma_{\eta}^{2}$ nor $\sigma_{\zeta}^{2}$ is highly statistically different than zero. However, a Wald test of the hypothesis that both parameters equal zero yields a chi-square statistic of 33.7 with two degrees of freedom. Therefore, it is concluded that the quarterly gross taxable gaming revenue series continues to follow a random walk process. Other summary measures of fit are comparable to the results in Table 1. 
TABLE 3

Parameter Estimates for Period 1967-I through 1990-IV.

\begin{tabular}{lrc}
\hline \hline Parameter & Estimate & Standard Error \\
\hline$\sigma_{\varepsilon}^{2}$ & 77.190 & 37.50 \\
$\sigma_{\eta}^{2}$ & 92.680 & 51.80 \\
$\sigma_{\xi}^{2}$ & 3.315 & 2.44 \\
$\sigma_{\omega}^{2}$ & 10.680 & 4.68 \\
\hline
\end{tabular}

$\mathrm{R}^{2}=.997$

$R^{2} \Delta 4=.728$

$\rho(1)=-.01$

Box-Ljung (12) $=11.96$

The multistep ahead forecasts of the updated structural time series model are presented in Table 4 . The first set of forecasts suggests that the model consistently overestimates gaming revenues. This overestimation could be a consequence of the recession, for example, and points out a shortcoming in univariate time series models vis-a-vis models that can incorporate more information about the economic structure generating the data (e.g., Cargill and Raffiee's approach). Yet the structural time series model is quickly adaptable, as shown by the second set of forecasts contained in Table 4. Here, knowledge of the forecast error in the first quarter of 1991 has been used in generating the forecasts for the remainder of the year. Note that these forecasts have been reduced by about 2 percent.

TABLE 4

Out-of-Sample Forecasts 1991-I through 1991-IV.

\begin{tabular}{lcccc}
\hline \hline Quarter & Actual & $\begin{array}{c}\text { Multistep Ahead } \\
\text { Forecasts-I }\end{array}$ & $\begin{array}{c}\text { Multistep Ahead } \\
\text { Forecasts-II }\end{array}$ \\
\hline 91-I & 1352.5 & $1391.8(2.9)^{2}$ & & \\
91-II & 1399.5 & $1425.7(1.9)$ & $1397.4(-0.2)$ \\
91-III & 1438.2 & $1494.9(3.9)$ & $1462.7 \quad(1.7)$ \\
91-IV & 1312.4 & $1410.9(7.5)$ & $1378.6 \quad(5.0)$ \\
\hline
\end{tabular}

${ }^{2}$ Percentage error of forecast.

\section{CONCLUSIONS}

Using time series models to forecast gaming revenues is not a new idea (Cargill and Eadington 1978). The use of the stochastic trend model, however, appears justified, given its interpretation as a local linear trend approximator. Con- 
sidering the nature of the gross taxable gaming revenue series, particular care should be taken when trying to apply standard econometric modeling methods. The possibilities for misspecification seem extensive in view of the changes that have occurred in the gaming industry during the last two decades. Furthermore, since the gross taxable gaming revenue series represents a mixture of other quantifiable measures and a conglomeration of different types of economic behavior (both by wagerers and casino operators), any explanation in terms of behavioral equations would have nowhere near the parsimony of the model adopted.

The structural time series approach should have broad applicability to forecasting the taxable sales of other types of service industries. In many cases, these sales have experienced periods of accelerating growth and have been differentially impacted by general business conditions. Since gaming is closely related to tourism, which itself represents a complex number of determining factors, similar success may be achieved using this methodology to model either the number of visitors or the sales of tourism-related industries at the local, state, or regional level.

\section{ENDNOTES}

1. For a detailed overview of the growth and importance of gaming and tourism for Nevada, see Ebel (1990).

2. A structural time series model can be considered to have a restricted autoregressive-moving average error model as its reduced form and should not be confused with structural econometric models.

3. The drop represents the amount of money either directly wagered or exchanged for chips at table games (craps, blackjack, roulette, baccarat, keno, and sports book). The handle represents the amount of money put into the slot machines.

4. It should be recognized that the value of univariate time series models is their short-term forecasting accuracy. These models may have quite different (disappointing) long-term forecast functions and certainly do not permit direct assessment of the effects of changing policies or other exogenous conditions.

\section{REFERENCES}

Cargill, T. F. "Is the Nevada Economy Recession Proof?" Nevada Review of Business and Economics (1979): 3-15 
Cargill, T. F., and W. R. Eadington. "Nevada's Gaming Revenues: Time Characteristics and Forecasting." Management Science 24 (1978): 1221-1230.

Cargill, T. F., and S. A. Morus. "A Vector Autoregression Model of the Nevada Economy." Economic Review, Federal Reserve Bank of San Francisco (1988): 21-32.

Cargill, T. F., and K. Raffiee. "The Nevada VAR Model: Update and General Observations." Nevada Review of Business and Economics (1990): 2-9.

Connaughton, J. E., and R. A. Madsen. "A Comparison of Regional Forecasting Techniques." The Review of Regional Studies 20 (1990): 4-11.

Durlauf, S. N., and P. C. B. Phillips. "Trends Versus Random Walks in Time Series Analysis." Econometrica 56 (1988): 1333-1354.

Eadington, W. R., and J. S. Hattori. "A Legislative History of Gambling in Nevada." Nevada Review of Business and Economics (1978): 13-17.

Ebel, R. D., ed. A Fiscal Agenda for Nevada. Reno: University of Nevada Press, 1990.

Engle, R. F., and C. W. J. Granger. "Co-integration and Error Correction: Representation, Estimation, and Testing." Econometrica 55 (1987): 251-276.

Harvey, A. C. Forecasting, Structural Time Series Models and the Kalman Filter.

New York: Cambridge University Press, 1989.

Harvey, A. C., and P. H. J. Todd. "Forecasting Economic Time Series with Structural and Box-Jenkins Models: A Case Study." Journal of Business and Economic Statistics 4 (1983): 299-309.

Horton, G. A. "Nevada Gaming Revenue (Win) Trends, Competitive Impacts on the Casino Gaming Industry, Gaming Control Board Regulation 6A and the Califomia Lottery: An Analytical Overview." Mimeo, undated. (Copies may be obtained by writing to the author of this manuscript.)

LeSage, J. P. "Forecasting Metropolitan Employment Using an Export-Base Error/Correction Model." Journal of Regional Science 30 (1990): 307-323.

Nelson, C. R., and H. Kang. "Spurious Periodicity in Inappropriately Detrended Time Series." Econometrica 49 (1981): 741-751.

Stock, J. H., and M. W. Watson. "Variable Trends in Economic Series." Journal of Economic Perspectives 2 (1988): 147-174.

Thompson, W. N. "Patterns of Public Response to Lottery, Horserace, and Casino Gambling Issues." Nevada Review of Business and Economics (1985): 12-22. 